\title{
10. COMPUTED TOMOGRAPHY (CT) SCAN IMAGE ANALYSIS OF SITE 808 CORES: STRUCTURAL AND PHYSICAL PROPERTY IMPLICATIONS ${ }^{1}$
}

\author{
Wonn Soh, ${ }^{2}$ Tim Byrne, ${ }^{3}$ Asahiko Taira, ${ }^{4}$ and Atsushi Kono ${ }^{5}$
}

\begin{abstract}
X-ray computed tomography $(\mathrm{CT})$ is a promising tool that yields data useful for understanding the fine-scale density structure of partly lithified and tectonically deformed sediments. We conducted 21 CT scans of ODP Leg 131 sediments, including whole-round cores and thin-section chips, obtained from the toe of the Nankai accretionary prism. The samples range from highly deformed pieces from the frontal thrust and décollement to homogeneous and essentially undeformed sediments above the frontal thrust and beneath the décollement. In the CT images, kink-like deformation bands and faults are recognized as obvious bright seams, bands, or stripes with relatively high linear attenuation coefficients. The differences in linear attenuation coefficients relative to the matrix range from $0.021 \mathrm{~cm}^{2} / \mathrm{g}$ (kink-like deformation band) to $0.038 \mathrm{~cm}^{2} / \mathrm{g}$ (fault). These data suggest a $0.10 \mathrm{~g} / \mathrm{cm}^{3}$ to $0.18 \mathrm{~g} / \mathrm{cm}^{3}$ increase in bulk density within the deformation structures, and they appear to be $13 \%$ and $33 \%$ more compacted than the nondeformed matrix, respectively. In contrast to the samples from the frontal thrust zone, CT images of the décollement sample exhibit relatively homogeneous textures. The attenuation coefficient of the sample of the décollement indicates bulk density and porosity values of $2.45 \mathrm{~g} / \mathrm{cm}^{3}$ and $18 \%$, respectively. The sample, hence, is approximately $50 \%$ more compacted than the sediment outside the décollement zone.
\end{abstract}

\section{INTRODUCTION}

Densification of sediments in accretionary prisms has been attributed to porosity reduction caused by differential stresses resulting from plate convergence. The process of densification plays an important role in dewatering and fluid migration of an accretionary prism. Few studies have investigated these processes (cf. Moore et al., 1986; Agar et al., 1989). To better understand these consolidation and dewatering processes, we applied X-ray computed tomography (CT) to sediments obtained from the Nankai accretionary prism during Leg 131 of the Ocean Drilling Program.

In this paper, we present CT scan images of the sediments of the Nankai accretionary prism that range from deformed to undeformed. The actual mode of the densification is estimated from the linear attenuation coefficient as well as from detailed microscopic-scale textural studies. We focus particularly on two types of structures, kink-like deformation bands and small-scale faults. Core-scale and microscopic-to-submicroscopic descriptions of these structures are provided in Taira et al. (1992), Maltman et al. (this volume), and Byrne et al. (this volume).

\section{BACKGROUND OF COMPUTED TOMOGRAPHY SCANNING}

An X-ray CT scanner is a device for reconstruction of an image of an object penetrated by X-rays, using the X-ray attenuation coefficients calculated from absorption or scattering. Although several published articles present the CT theory (e.g., Brooks and DiChiro, 1975, 1976; Iwai, 1979), we include a brief discussion of CT theory. The principal behind computed tomography is based on the mathematical theory established by J. Radon in 1917. He showed that twoor three-dimensional images of an object can be reconstructed from

\footnotetext{
${ }^{1}$ Hill, 1.A., Taira, A., Firth, J.V., et al., 1993. Proc. ODP, Sci. Results, 131: College Station, TX (Ocean Drilling Program).

${ }^{2}$ Institute of Geosciences, Shizuoka University, Japan.

${ }^{3}$ Department of Geology and Geophysics, University of Connecticut, Storrs, CT 06269, U.S.A.

${ }_{5}^{4}$ Ocean Research Institute, University of Tokyo, Japan.

${ }^{5}$ Technical Research Center, Japan National Oil Corporation, Japan.
}

an infinite number of its projection data. The image reconstruction of an object is performed with a permissible limit of error in a CT scanner because an infinite number of the projection data of an actual sample is available.

A collimated X-ray beam of intensity $I_{o}$, as a result of passing through a sample of material of thickness $D$, yields a linearly attenuated beam of intensity $I$, behind the sample. The relationship is shown below:

$$
I=I_{o} \exp (-\mu D)
$$

where the linear attenuation coefficient is $\mu$. A CT scan image of the object is obtained as a map of linear attenuation coefficients for any desired section (slice) of the sample. When the sample material is heterogeneous in composition and density over the distance $D$, as in a sample of real sediment, particularly for a deformed sample, the attenuation coefficient will vary in the region of imaging. A more general expression is

$$
I=I_{o} \exp \left(-\int_{0}^{D} \mu(x) d x\right)
$$

where $x$ is the distance from the $\mathrm{X}$-ray source which varies between 0 and $D$; sample thickness. Numerous beams are passed through the sample at various angles $\left(0^{\circ}-180^{\circ}\right)$, thus, the distribution of the attenuation coefficients at discrete points within the sample can be determined.

The CT scan system used in this study is a JACK-320 (Toshiba TOSCANNER 23201 system) housed in Technology Research Center, Japan National Oil Corporation (JNOC), Chiba. It is an upgraded second-generation rotation traverse type CT scanner. The JACK-320, designed especially for scanning lithified (hard) rock samples, uses a strong $(320 \mathrm{kVp}$ ) peak energy of radiation (Table 1). The JACK-320 scanner converts the linear attenuation coefficients into corresponding numerical values (CT value). The raw data of the linear attenuation coefficients are displayed on a $512 \times 512$ matrix on a gray-level viewing system. Additional adjustment of the $C T$ value level creates the most suitable image. Zones of high linear attenuation coefficients are displayed as bright zones on the CT scan image.

We reconverted the CT values into linear attenuation coefficients. In the conversion, an attenuation coefficient of water (reference material) of $0.137 \mathrm{~cm}^{2} / \mathrm{g}$ was adopted, assuming that $200 \mathrm{kV}(65 \%$ of 
Table 1. Capability of X-ray CT scanner (JACK-320).

Generation: second generation
rotation-scanning object $\left(0^{\circ}\right.$ to $\left.180^{\circ}\right)$
traverse-X-ray source and detector
X-ray energy: $320 \mathrm{kVp}$ (maximum)
X-ray detector: scintillator 64 channels
Penetrability: $150 \mathrm{~mm}$ aluminium
Maximum scan field: $250 \mathrm{~mm}$ (diameter) by $600 \mathrm{~mm}$ (length)
Slice width: $1,2,4 \mathrm{~mm}$ (changeable)
Inspection time: $2 \mathrm{~min} /$ slice
Display: 512 by 512 (matrix)
Monitor: 256 (gray-level)

the peak radiation energy) corresponds to the value of the actual radiation energy at $320 \mathrm{kVp}$ of the JACK-320 scanner.

\section{SAMPLE MATERIALS}

Twenty-one samples from ODP Leg 131, Site 808, drill cores obtained from the toe of the Nankai accretionary prism were scanned in this study (Fig. 1). The reader should refer to Taira, Hill, Firth, et al. (1991) concerning the background and descriptions of the drill cores. The samples scanned in this study comprise 18 mudstones, 2 volcaniclastics, and 1 mudstone intercalated with volcaniclastic layers. Coarse-grained sediments, such as trench fill turbidites, were excluded from the scanning. The samples scanned were $2 \mathrm{in}$. diameter unsplit, whole-round cores, and the core chips more than $1 \mathrm{in.} \mathrm{long.}$ The sample surfaces were coated by paraffin to prevent dehydration. Sample dimensions are not uniform, particularly in length, but all of them were large enough for scanning (Table 1). In addition, acrylic sample of $1.19 \mathrm{~g} / \mathrm{cm}^{3}$ density of the same diameter was scanned for reference (Table 2). After CT scanning the samples, several core samples were cut and polished for photography. A small amount of water was sprayed on the sample surface to make the deformation structures more visible during photography.

The linear attenuation coefficient was obtained as an average over a domain of suitable size, ranging from 50 to 150 pixels ( 1.5 to $4.5 \mathrm{~mm}^{2}$ in dimension), from the nondeformed matrix, excluding deformation structure zones. Furthermore, we selected the domains not along the margin but around the central part of the core sample to take away the influence of "beam-hardening." The results of repeated scanning demonstrate that the method showed good reproducibilities for the average attenuation coefficient. The relatively high variation in standard deviation values of the samples (Table 2) is partly due to the mechanical difficulty of JACK-320 in cancelling random errors completely during computing. On the other hand, the linear attenuation coefficient of the deformed part was obtained at the limited small domain, ranging from one to a few pixels $\left(0.03\right.$ to $0.10 \mathrm{~mm}^{2}$ in dimension), within the faults and kink-like deformation bands.

In this paper, we regarded the linear attenuation coefficient obtained from the nondeformed matrix as the average linear attenuation coefficient of the sample, because the influences of the deformation zones are negligibly small in these areas.

\section{RESULTS}

Figure 2 shows three examples of CT scan images of deformed sediment samples, showing the JACK-320 resolution. Comparison of the CT scan image to the photography shows that the CT scan images the thin sand layers, faults, kink-like deformation bands, and open fractures (cf. Maltman et al., this volume). The samples were divided into two types based on the CT scan images: deformed and the slightly deformed to undeformed sediments. Approximately one-third of the samples were collected from the frontal thrust and its adjacent zones. The slightly deformed or undeformed sediments, however, are observed primarily from samples above the frontal thrust, and above and below the décollement. Mesoscopic and microscopic shipboard ob- servations suggest that the sediments below the décollement are less deformed (e.g. Taira et al., 1992). The CT scan images, such as Sample 131-808C-102R-1, also support this interpretation.

The 13 undeformed and slightly deformed samples obtained between 43 and 1263 mbsf were scanned, including two volcaniclastic samples (Fig. 1). Overall, the CT scan images of these samples show homogeneous textures. The uppermost sample (131-808A-5H-6), however, has a partly heterogeneous texture probably resulting from bioturbation such as worm tube traces. Judging from the 13 examples, the heterogeneity in texture tends to decrease with burial depth. Alternatively, very bright spots in CT image, probably authigenic pyrite, occur in the homogeneous texture from the upper middle horizon of the drill cores such as Sample 131-808C-43R-2. The increase in linear attenuation coefficient of the sediment samples does not correspond directly with increase in burial depth. For example, the average linear attenuation coefficients obtained from sediments around the frontal thrust zone and décollement (e.g., Sample 131808C-8R-1, 12-114 cm, Core 131-808C-66R-4, and Sample 131$808 \mathrm{C}-69 \mathrm{R}-2,74-74 \mathrm{~cm})$ are obviously higher than those of the underlying sediments (Table 2).

The CT scan images of the deformed sediment samples display bright seams, bands, or stripes, and "phacoidal structure" (Fig. 3). In the photographs, these deformation structures are recognized by their slight opaque coloration. The kink-like deformation bands and faults can be identified based on the difference in fabric and brightness on the CT scan image. For example, the deformation bands are observed as a series of bright seams, but less bright than the faults. The differences in linear attenuation coefficient between the deformation structures and the nondeformed matrix, excluding the kink-like deformation bands and faults, range from 0.021 to $0.038 \mathrm{~cm}^{2} / \mathrm{g}$.

CT images of the sediments from the décollement show a homogeneous texture (Fig. 2), distinctly different from the well-developed faults and kinks observed throughout the cores above the décollement. At the scale of the core barrel, the décollement sediments display a scaly fabric defined by an irregular, anastomosing network of curviplanar fracture surfaces (e.g., Taira et al., 1992). At a microscopic scale, the sediment of the décollement zone is characterized by a curious mottled or domainal texture associated with irregular and discontinuous sets of shear surfaces (cf. PI. 3; Byrne et al., this volume). The CT image is consistent with these observations and suggests a difference in the deformation processes between the décollement and frontal thrust zones. The décollement sample has an average linear attenuation coefficient value of $0.406 \mathrm{~cm}^{2} / \mathrm{g}$, which is the highest attenuation coefficient value obtained at Site 808 . The next highest value also comes from just above the décollement (Core 131$808 \mathrm{C}-66 \mathrm{R}-4)$ and probably reflects progressive deformation and consolidation near the décollement.

\section{DISCUSSION}

The average linear attenuation coefficient and bulk density for the Leg 131 core samples shows a positive linear relationship (Fig. 4). In constructing these correlations we used bulk density data collected on the JOIDES Resolution (Taira, Hill, Firth, et al., 1991); these measurements were usually taken within a few to tens of centimeters from the CT samples. The resulting relationship between the bulk density $\left(\rho_{\text {sample }}\right)$ and the average linear attenuation coefficient ( $\mu$ sample) can be approximately shown as:

$$
\rho_{\text {sample }}=0.49+4.83 \mu \text { sample }\left(r^{2}=0.80\right)
$$

Similar empirical relations between bulk densities and attenuation coefficients have been studied using a X-ray CT scanner in the soil sciences (Petrovic et al., 1982; Crestana et al., 1985; Wanner et al., 1989). Anderson et al. (1988) showed clearly that the attenuation coefficients of the Mexico and Crinder soils increase linearly with increasing bulk densities. 


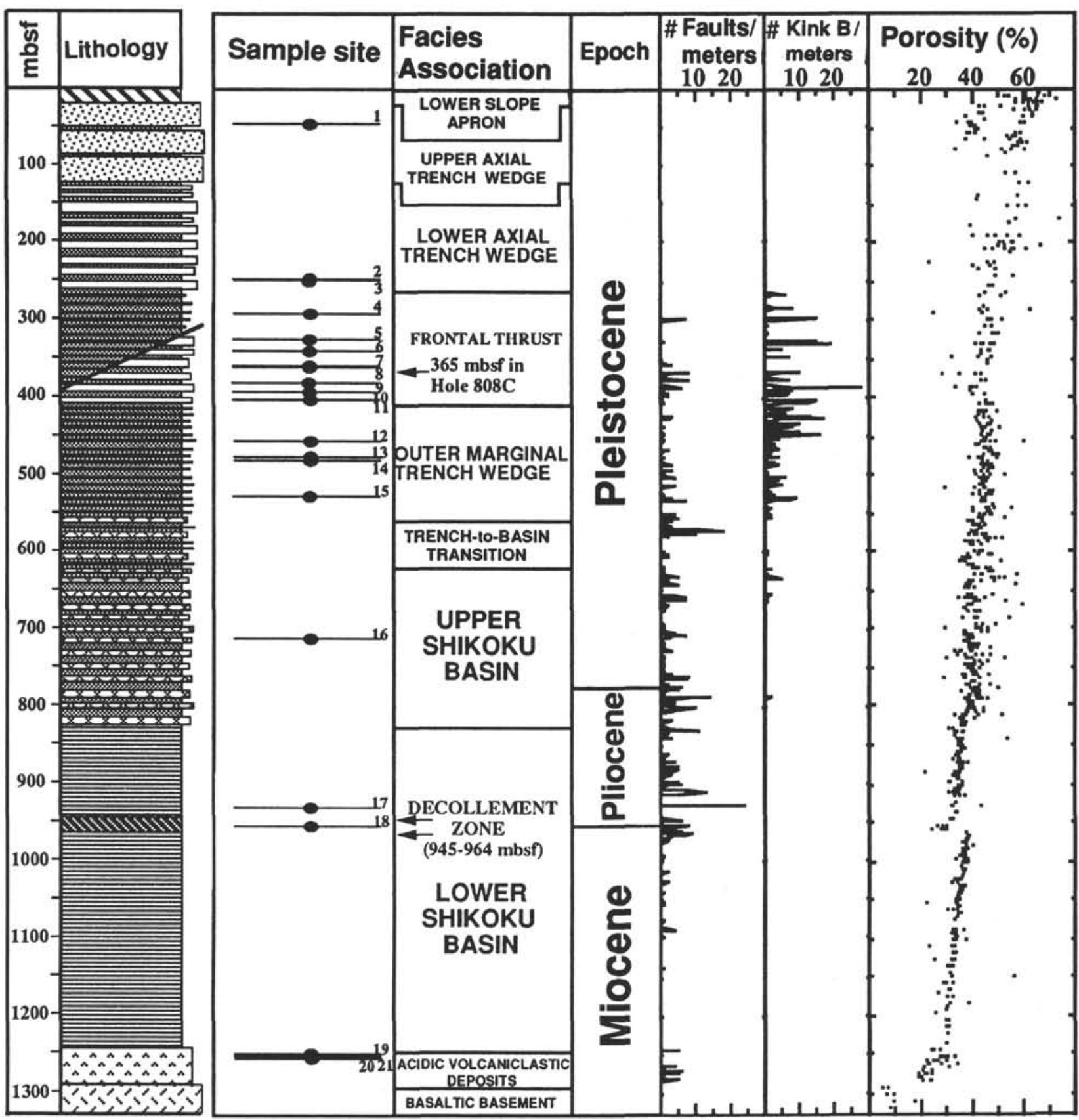

Figure 1. Outline of sedimentary facies, structural, and physical properties of Site 808. The CT scan sample sites are plotted by points.

SEM, microprobe, and thin-section studies show that densification of the sediment is due to a reduction in porosity (Byrne et al., this volume). It suggests that the linear attenuation coefficient increase in the microstructures is attributed to an increase in densification from porosity reduction. Using equation (3), we estimated the density increase in the microstructures relative to the nondeformed matrix ranging from $0.10 \mathrm{~g} / \mathrm{cm}^{3}$ (kink-like deformation bands) to $0.18 \mathrm{~g} / \mathrm{cm}^{3}$ (faults), and corresponding porosity reductions relative to nondeformed matrix ranging from $6 \%$ (kink-like deformation bands) to $13 \%$ (faults). As mentioned before, we utilized all of the shipboard porosity and density data to estimate the relation between the porosity and the bulk density of Leg 131 samples. The resulting relation was found to be:

$$
\text { porosity }=171.544-62.798 r_{\text {sample }}\left(r^{2}=0.899\right) \text {. }
$$

Further,

$$
\operatorname{DC}(\%)=100 \times\left(\mathrm{n}_{\mathrm{m}}-\mathrm{n}_{\mathrm{d}}\right) /\left(\mathrm{n}_{\mathrm{m}}\right)
$$

where $\mathrm{n}_{\mathrm{m}}$ and $\mathrm{n}_{\mathrm{d}}$ are the matrix and deformation structure porosities, respectively. The differential compaction ratio (DC), defined above, was calculated as approximately $13 \%$ for the kink-like deformation bands and $33 \%$ for the faults.

However, the attenuation coefficient is also influenced by differences in the chemical composition of material, because the linear attenuation coefficient is a function of effective atomic number of an absorbing material when density and photon energy are held constant (e.g., Pogossian et al., 1977). This is mainly attributed to interaction of X-ray energy and the material, such as the photoelectric effect and Compton and Thomson scatterings. The presence of 
Table 2. List of the core samples for the CT scan measurements.

\begin{tabular}{|c|c|c|c|c|c|c|}
\hline $\begin{array}{l}\text { Hole, core, section, } \\
\text { interval }(\mathrm{cm})\end{array}$ & $\begin{array}{l}\text { Attenuation } \\
\text { (matrix) } \\
\left(\mathrm{cm}^{2} / \mathrm{g}\right)\end{array}$ & $\begin{array}{c}\text { Standard dev. } \\
\text { (matrix) } \\
\left(\mathrm{cm}^{2} / \mathrm{g}\right)\end{array}$ & $\begin{array}{l}\text { Attenuation } \\
\text { (deformed part) } \\
\left(\mathrm{cm}^{2} / \mathrm{g}\right)\end{array}$ & $\begin{array}{l}\text { Depth } \\
\text { (mbsf) }\end{array}$ & $\begin{array}{l}\text { Bulk density }{ }^{\mathrm{a}} \\
\left(\mathrm{g} / \mathrm{cm}^{3}\right)\end{array}$ & $\begin{array}{l}\text { Porosity } \\
(\%)\end{array}$ \\
\hline \multicolumn{7}{|l|}{$131-$} \\
\hline $808 \mathrm{~A}-5 \mathrm{H}-6$ & 0.287 & 0.044 & & 43.20 & 1.77 & 60.40 \\
\hline $808 \mathrm{~B}-17 \mathrm{X}-2,39-44$ & 0.278 & 0.033 & & 265.38 & 1.82 & 44.80 \\
\hline $808 B-17 X-4,41-47$ & 0.328 & 0.021 & 0.366 (fault) & 268.34 & 2.00 & 42.60 \\
\hline $808 C-1 R-1,95-97$ & 0.326 & 0.018 & 0.347 (kink) & 299.48 & 1.97 & 46.30 \\
\hline $808 \mathrm{~B}-24 \mathrm{X}-3,71-74$ & 0.334 & 0.017 & 0.360 (kink) & 331.00 & 1.99 & 48.60 \\
\hline $808 C-6 R-1,46-50$ & 0.275 & 0.027 & & 347.00 & 1.57 & 32.20 \\
\hline $808 \mathrm{C}-8 \mathrm{R}-1,112-114$ & 0.368 & 0.008 & 0.402 (fault) & 367.20 & 2.10 & \\
\hline $808 \mathrm{C}-8 \mathrm{R}-3$ & 0.269 & 0.010 & & 369.00 & & \\
\hline $808 \mathrm{C}-10 \mathrm{R}-1,20-38$ & 0.315 & 0.021 & 0.353 (fault) & 386.35 & 2.07 & 40.00 \\
\hline $808 \mathrm{C}-11 \mathrm{R}-2,6-8$ & 0.312 & 0.024 & 0.342 (kink) & 396.36 & 2.08 & 40.00 \\
\hline $808 \mathrm{C}-12 \mathrm{R}-3,46-49$ & 0.287 & 0.036 & & 408.00 & 2.01 & 45.50 \\
\hline $808 C-18 R-1,148-150$ & 0.334 & 0.022 & & 463.88 & 1.99 & 45.60 \\
\hline $808 \mathrm{C}-19 \mathrm{R}-3,133-144$ & 0.259 & 0.035 & $0.293(?)$ & 476.54 & 2.02 & 43.90 \\
\hline $808 \mathrm{C}-20 \mathrm{R}-5,12-16$ & 0.275 & 0.034 & & 488.00 & 1.99 & 44.60 \\
\hline $808 \mathrm{C}-25 \mathrm{R}-1,25-32$ & 0.277 & 0.034 & $0.306(?)$ & 530.25 & 2.00 & 44.70 \\
\hline $808 \mathrm{C}-44 \mathrm{R}-3,132-135$ & 0.313 & 0.028 & & 716.70 & 2.11 & 37.80 \\
\hline $808 \mathrm{C}-66 \mathrm{R}-4$ & 0.397 & 0.034 & & 930.00 & 2.23 & 31.90 \\
\hline $808 \mathrm{C}-69 \mathrm{R}-2,72-74$ & 0.406 & 0.021 & & 956.05 & & \\
\hline $808 \mathrm{C}-101 \mathrm{R}-4,81-96$ & 0.356 & 0.029 & & 1257.40 & 2.32 & 26.40 \\
\hline $808 \mathrm{C}-101 \mathrm{R}-3,120-124$ & 0.314 & 0.033 & & 1256.38 & 2.16 & 30.00 \\
\hline $808 \mathrm{C}-102 \mathrm{R}-1,115-120$ & 0.352 & 0.028 & & 1262.60 & 2.23 & 34.40 \\
\hline Acrylic (standard) & 0.171 & 0.068 & & & 1.19 & \\
\hline
\end{tabular}

${ }^{a}$ From Taira et al. (1992).

high atomic number elements, therefore, increases the attenuation coefficient of the sample even if the bulk density is unchanged.

Hence, the relatively high linear attenuation coefficient of the deformation structures may be related to an enrichment in elements with high atomic number, such as $\mathrm{Fe}$ and $\mathrm{Mn}$. However, if Fe content increases due to precipitation from the interstitial fluid within the deformation structures, an approximately $6 \mathrm{wt} \%$ (for the kink-like structures) to $10 \mathrm{wt} \%$ (for the faults) in $\mathrm{Fe}$ content relative to the matrix is needed to cause the observed change in the attenuation coefficient (cf. fig. 6 in Anderson et al., 1988). At present, microprobe and backscatter SEM studies have failed to document a significant increase of $\mathrm{Fe}$ of this magnitude within the deformation structures (cf. Byrne et al. this volume).

The décollement zone also shows a substantial reduction in porosity based on CT scan data. To estimate the precise porosity reduction rate at the décollement, we scanned a fragment of "scaly" interval that was bounded on both sides by scaly cleavages (Section 131-808C69R-2) (Fig. 2). The average linear attenuation coefficient for this sample is $0.406 \mathrm{~cm}^{2} / \mathrm{g}$, the highest value of all scanned samples. Using equations (3) and (4), we estimated a density of $2.45 \mathrm{~g} / \mathrm{cm}^{3}$ and a porosity of $18 \%$ for this sample. The shipboard porosity data for samples within the décollement range from $24 \%$ to $30 \%$. Thus, the CT scan data yield porosities that are slightly lower than the shipboard measurements. Sediments above the décollement have porosities that range from $32 \%$ to $38 \%$ (Taira et al., 1992). Hence, the fragment of "scaly" interval in the décollement zone is significantly more compacted than the sediment outside the décollement zone.

This estimate of a differential compaction for the décollement assumes a uniform composition across the décollement zone and preliminary chemical data support this assumption. Underwood et al. (this volume) suggest that the clay mineral composition is constant across the décollement. Pickering et al. (this volume) demonstrates that major element composition of the sediments is similar to the sediments above and below the décollement. Moreover, Pickering et al. (this volume) recognized a positive REE anomaly at the décollement zone, however this anomaly in REE appears to be too small (e.g., less than $10 \mathrm{ppm}$ even in $\mathrm{Ce}$ ) to explain the high attenuation coefficient. Hence, it is most likely that the value of the high attenuation coefficient measured at the décollement can be explained mainly by porosity reduction. Maltman et al. (this volume) and Byrne et al. (this volume) also have shown that there is substantial evidence for collapse and consolidation of the phyllosilicate framework within the décollement zone, which is consistent with our interpretation of the attenuation coefficient values for the zone. Byrne et al. (this volume) also have proposed that the microscopic and submicroscopic textures indicate a cyclic history of collapse, consolidation, and dewatering followed by fluid infiltration, high pore pressures, and collapse. This cyclic history of deformation may account for the unusually high densities and attenuation coefficients within the décollement.

\section{SUMMARY AND CONCLUSIONS}

The advanced CT scanner can produce a high-resolution, crosssectional image of both partly and completely lithified sediments without destroying the structural integrity of the sample. The scanner therefore provides a powerful tool for the quantitative analysis of tectonic microstructures. In particular, CT scanning is most useful for estimating the detailed density structure associated with individual deformational structures. In this study, we demonstrated a change in linear attenuation coefficients within kink-like deformation bands and faults relative to the nondeformed matrix. These differences ranges from 0.021 to $0.038 \mathrm{~cm}^{2} / \mathrm{g}$. Although further study, particularly of the chemical composition that may influence the X-ray attenuation coefficients, is needed, we consider the increase in attenuation to be primarily a result of consolidation and reorientation of detrital phyllosilicates. The linear attenuation coefficients for the deformation structures also suggest density and porosity differences of $0.10 \mathrm{~g} / \mathrm{cm}^{3}$ and $0.18 \mathrm{~g} / \mathrm{cm}^{3}$ for the structures, respectively, relative to the nondeformed matrix. In total, therefore, the kink-like structures and faults appear to be $13 \%$ and $33 \%$ more compacted than the nondeformed matrix.

Finally, the result of the CT scan study suggests a bulk density for the sediment at the décollement of $2.45 \mathrm{~g} / \mathrm{cm}^{3}$, which approximately corresponds to a porosity of $18 \%$. This is the lowest porosity value of all of the data from Leg 131, including the samples from the highly deformed frontal thrust. Moreover, the CT images suggest that the high attenuation coefficients measured at the décollement could be explained mainly by porosity reduction at the décollement zone. CT scans show little evidence for discrete fault zones that is consistent with microscopic evidence for heterogeneity within the décollement. 


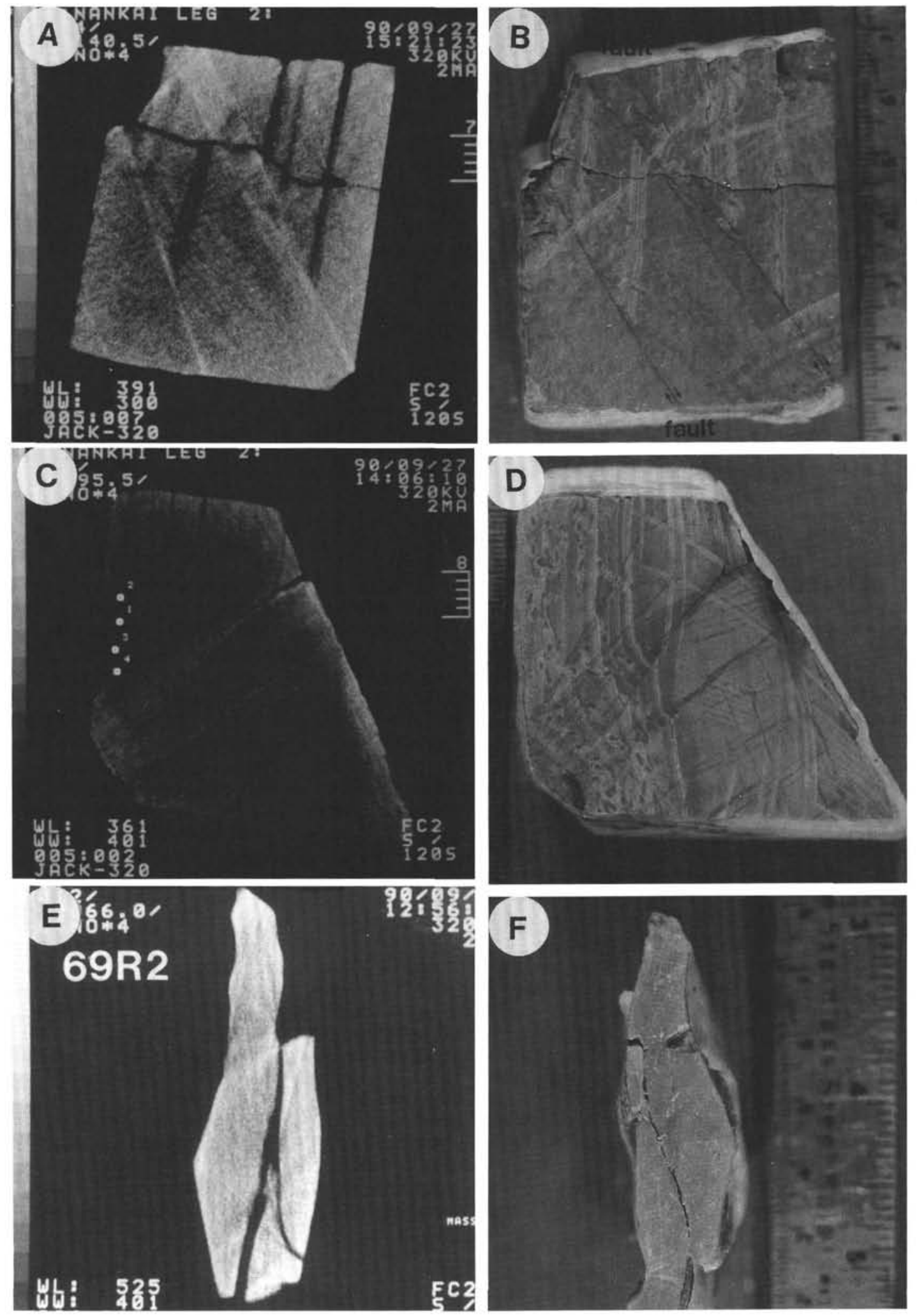

Figure 2. Comparison between the CT scan and photographic images of various samples suggests that the resolution of the CT scan image is particularly useful in identification of the fractures. Such high-resolution cross-sectional images of the lithified sediments are obtained without destroying them and any preparation. A. An example of the CT scan image showing minor dislocation of the tuffaceous layers due to faults. The sample is obtained near the frontal thrust zone. Marginal bright zone is due to noise (beam hardening effect). B. Photograph demonstrating that the CT scan image correctly emphasizes the fault and tuff layer images. The white surrounding cover is a kind of wax. C. CT scan image showing shear bands in the laminated mudstone. This was specially focused with the intention of emphasizing shear bands. The sample is obtained from the frontal thrust zone. D. Photograph of the same sample. E. CT scan image of the sediment obtained from the décollement. F. Photograph of the same décollement sample. 


\section{ACKNOWLEDGMENTS}

We thank the members of Leg 131 scientific party, technicians, and crew. This study was supported by Technology Research Center, Japan National Oil Corporation, including the support of Satoru Onoe, Hideaki Ishii, and Toshiyuki Hagiwara. In particular, H. Ishii and T. Hagiwara assisted us with the theoretical and technical aspects in use of the CT scanner. Further, the study was also supported through grants to Byrne by the Japan Society for the Promotion of Science and the Joint Oceanographic Institutes. All help mentioned is gratefully acknowledged.

\section{REFERENCES}

Agar, S.M., Prior, D.J., and Behrmann, J.H., 1989. Back-scattered electron imagery of the tectonic fabrics of some fine-grained sediments: implications for fabric nomenclature and deformation processes. Geology, 17:901-904.

Anderson, S.H., Gantzer, C.J., Boone, J.M., and Tully, R.J., 1988. Rapid nondestructive bulk density and soil-water content determination by computed tomography. Soil. Sci. Soc. Am. J., 52:35-40.

Brooks, R.A., and Di Chiro, G., 1975. Theory of image reconstruction in computed tomography. Radiology, 117:561-572.

, 1976. Principles of computer assisted tomography (CAT) in radiographic and radioisotopic imaging. Phys. Med. Biol., 21:689-732.

Crestana, S., Mascarenhas, S., and Pozzi-Mucelli, R.S., 1985. Static and dynamic three-dimensional studies of water in soil using computed tomographic scanning. Soil. Sci., 140:326-332.

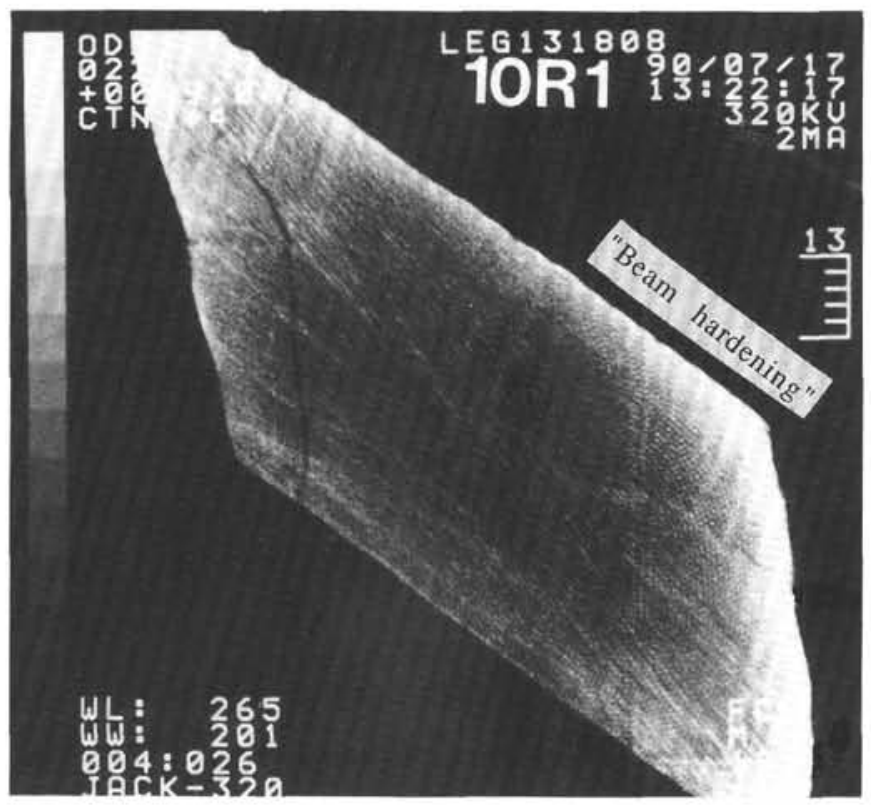

Figure 3. Transverse CT scan image of the deformed sediment sample at the frontal thrust zone, showing "phacoidal" structure. As a result of "beam hardening," the bright zone is formed along the margin, which is an artifact of unequal filtration of the polychromatic X-ray beam.
Holler, P., and Kogler, F.-C., 1990. Computed tomography: a nondestructive, high-resolution technique for investigation of sedimentary structures. Mar. Geol., 91:263-266.

Iwai, Y., 1979. CT Scanner-X-ray Computed Tomography Scanner: Tokyo (Corona-sha Publ.). (In Japanese)

Moore, J.C., Roeske, S., Lundberg, N., Schoonmaker, J., Cowan, D., Gonzales, E., and Lucas, S., 1986. Scaly fabrics from Deep Sea Drilling Project cores from forearcs. In Moore, J.C. (Ed.), Structural Fabrics Preserved in Deep Sea Drilling Project Cores From Forearcs. Mem.-Geol. Soc. Am., 166:55-73.

Pogossian, T., Phelps, M.M., and Browell, G.L., 1977. Reconstruction Tomography in Diagnostic Radiology and Nuclear Medicine: Baltimore (Univ. Park Press).

Taira, A., Hill, I., Firth, J., Berner, U., Brückmann, W., Byrne, T., Chabernaud, T., Fisher, A., Foucher, J.-P., Gamo, T., Gieskes, J., Hyndman, R., Karig, D., Kastner, M., Kato, Y., Lallement, S., Lu, R., Maltman, A., Moore, G., Moran, K., Olaffson, G., Owens, W., Pickering, K., Siena, F., Taylor, E., Underwood, M., Wilkinson, C., Yamano, M., and Zhang, J., 1992. Sediment deformation and hydrogeology of the Nankai accretionary prism: synthesis of shipboard results of ODP Leg 131. Earth Planet. Sci. Lett., 109:431-450.

Wanner, G.S., Nieber, J.L., Moore, I.D., and Geise, R.A., 1989. Characterizing macropores in soil by computed tomography. Soil. Sci. Soc. Am. J., 53:653-660.

Date of initial receipt: 7 October 1991

Date of acceptance: 8 October 1992

Ms 131SR-113

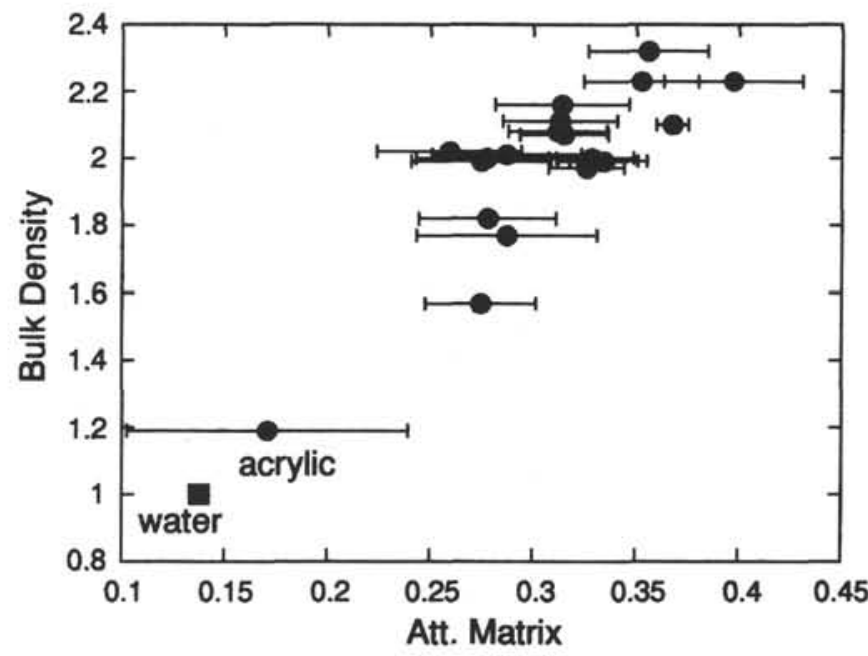

Figure 4. Relationship between the bulk density and the linear attenuation coefficient showing a negative linear relation. 